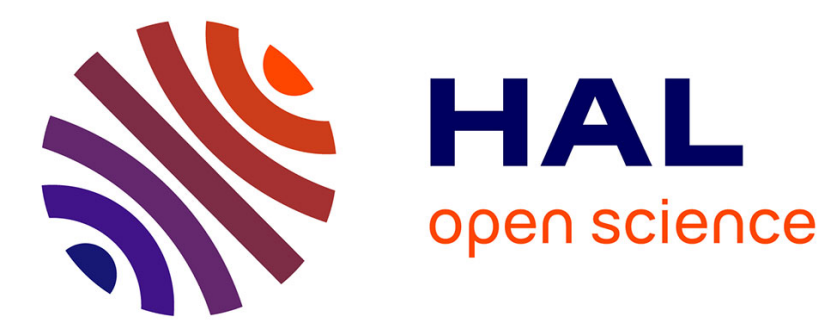

\title{
Role of carboxylate chelating agents on the chemical, structural and textural properties of hydroxyapatite
}

Karima Achelhi, Sylvie Masse, Guillaume Laurent, Ahmed Saoiabi, Abdelaziz Laghzizil, Thibaud Coradin

\section{- To cite this version:}

Karima Achelhi, Sylvie Masse, Guillaume Laurent, Ahmed Saoiabi, Abdelaziz Laghzizil, et al.. Role of carboxylate chelating agents on the chemical, structural and textural properties of hydroxyapatite. Dalton Transactions, 2010, 39 (44), pp.10644-10651. 10.1039/c0dt00251h . hal-02291327

\section{HAL Id: hal-02291327 https://hal.sorbonne-universite.fr/hal-02291327}

Submitted on 29 Sep 2020

HAL is a multi-disciplinary open access archive for the deposit and dissemination of scientific research documents, whether they are published or not. The documents may come from teaching and research institutions in France or abroad, or from public or private research centers.
L'archive ouverte pluridisciplinaire HAL, est destinée au dépôt et à la diffusion de documents scientifiques de niveau recherche, publiés ou non, émanant des établissements d'enseignement et de recherche français ou étrangers, des laboratoires publics ou privés. 


\title{
Role of carboxylate chelating agents on the chemical, structural and textural properties of hydroxyapatite $\uparrow$
}

\author{
Karima Achelhi, ${ }^{a, b}$ Sylvie Masse, ${ }^{b}$ Guillaume Laurent, ${ }^{b}$ Ahmed Saoiabi, ${ }^{a}$ Abdelaziz Laghzizil ${ }^{* a}$ and Thibaud \\ Coradin $* b$
}

Organically-modified hydroxyapatite materials were synthesized through the addition of oxalic, succinic, adipic and citric acids to a calcium hydroxide solution before neutralization by ammonium dihydrogenphosphate. All carboxylic acids have a significant influence on apatite crystallinity and nanoparticle size, as indicated by XRD and TEM. Chemical and thermogravimetric analyses as well as FTIR and $\left\{{ }^{1} \mathrm{H}\right\}-{ }^{13} \mathrm{C} C \mathrm{CP}$ MAS NMR spectroscopies indicate that the additives are present in the final material. ${ }^{1} \mathrm{H},\left\{{ }^{1} \mathrm{H}\right\}-{ }^{31} \mathrm{P}$ HPDec MAS, CP MAS and $2 \mathrm{D}\left\{{ }^{1} \mathrm{H}\right\}{ }^{-31} \mathrm{P}$ CP-HETCOR MAS NMR

experiments suggest that carboxylic acids are localized on the apatite nanocrystallite surface, resulting in the formation of a disordered outer layer. Nitrogen sorption measurements indicate minor modifications of the specific surface area of the resulting mesoporous materials upon carboxylic acid addition but more significant variations in the average dimensions of the pores as well as in the chemical nature of the pore surface. Although these evolutions are mainly in good agreement with the ligand affinity for calcium ions in solution, an unexpected difference was observed between succinic and adipic acid, that may be attributed to steric constraints resulting from the interfacial nature of the calcium-ligand interactions. These data should provide useful guidelines to identify novel efficient additives to control apatite growth.

\section{Introduction}

Nowadays, many synthetic bone substitutes based on calcium phosphate, and especially hydroxyapatite, are available to repair tissues that are lost or damaged. ${ }^{1-3}$ The solubility and reactivity of hydroxyapatite (HAp) vary with different factors such as porosity, grain size and crystallinity., ${ }^{4,5}$ In addition, porous hydroxyapatites are well-known for their surface-binding and cation-exchange properties towards various organic and inorganic substances. $^{6-9}$ Further improvement of surface properties can be reached by grafting apatite with organic or biological moieties. ${ }^{10-15}$ However, very few studies have been devoted to the one step modification, i.e. incorporation of the organic function during apatite formation, of HAp materials. One possibility is to use organophosphate molecules that replace part of the inorganic phosphate precursor. ${ }^{16-18}$ Such procedures not only allow the homogeneous grafting of the organic function over the whole material volume but, because the organophosphonates can inhibit the growth of calcium phosphate particles, they significantly modify the HAp porous structure. An alternative strategy relies on the simultaneous surface functionalization and structural control

${ }^{a}$ Laboratoire de Chimie Physique Générale, Département de Chimie, Faculté des Sciences, BP 1014, Rabat, Marocco.E-mail: laghzizi@hotmail.com; Fax: +212537775440

${ }^{b} U P M C$ Univ Paris 06; CNRS, Chimie de la Matière Condensée de Paris, College de France, 11 place Marcelin Berthelot, F-75005, Paris, France. E-mail: thibaud.coradin@upmc.fr.; Fax: +33 144271443; Tel: +33 144271528 of apatite using calcium-chelating agents. ${ }^{19-21}$ For this purpose, carboxylic acids appear as most promising additives due to their strong affinity for calcium ions and apatite surface. ${ }^{22-27}$

In this work, we have evaluated a series of dicarboxylic acids of increasing chain length, i.e. oxalic, succinic and adipic acids on hydroxyapatite formation and compare their influence to citric acid, a tricarboxylic acid (Scheme 1). Our data suggest that these acids are able to interact with calcium ions present on the surface of growing apatite nanoparticles, leading to a modification of particle size and chemical nature. By doing so, they also impact on the textural features of the materials. When the different carboxylic acids are compared, it is observed that the relative ligand-calcium affinity in solution and on the apatite surface can significantly differ. This suggests that further identification of molecular inhibitors of apatite growth should take into account 
the specific constraints of the heterogeneous solid-liquid interface, in particular the conformational flexibility of the ligand.

\section{Experimental}

\section{Preparation of organically-modified hydroxyapatites}

The pure hydroxyapatite (HAp) was prepared by a modified chemical wet method previously reported. ${ }^{17} 1.67$ moles of $\mathrm{Ca}(\mathrm{OH})_{2}$ and 1 mole of $\mathrm{NH}_{4} \mathrm{H}_{2} \mathrm{PO}_{4}$, corresponding to the hydroxyapatite stoichiometric ratio of $\mathrm{Ca} / \mathrm{P}=1.67$, were independently dissolved in deionized water at room temperature. The phosphoruscontaining solution was quickly added to the calcium solution and the mixture was stirred for $1 \mathrm{~h}$ at $25^{\circ} \mathrm{C}$. The final suspensions were aged for $48 \mathrm{~h}$ at room temperature, filtered and thoroughly washed with deionized water. The recovered precipitate (HAp) was dried overnight at $100{ }^{\circ} \mathrm{C}$ in an oven. The carboxylate-modified hydroxyapatites were obtained following a similar procedure as for pure HAp except for the calcium-containing solutions that were prepared by adding 0.25 mole of carboxylic acid to the $\mathrm{Ca}(\mathrm{OH})_{2}$ solution that was left under stirring for one hour. Resulting powders were termed o-HAp (oxalic acid), s-HAp (succinic acid), a-HAp (adipic acid) and c-HAp (citric acid).

\section{Characterization techniques}

The crystalline phases were identified using a powder X-ray diffractometer (XRD) (Philips PW131 diffractometer). Infrared spectra were recorded from $400 \mathrm{~cm}^{-1}$ to $4000 \mathrm{~cm}^{-1}$ on a Brüker IFS 66v Fourier transform spectrometer using $\mathrm{KBr}$ pellets. The $\mathrm{N}_{2}$ adsorption-desorption isotherms for dried powders were obtained by multi-point $\mathrm{N}_{2}$ gas sorption experiments at $77 \mathrm{~K}$ using a Micromeritics ASAP 2010 instrument. The specific surface areas were calculated according to the Brunauer-Emmett-Teller (BET) method using adsorption data in the relative pressure range from 0.05 to 0.25 whereas the pore size and volume were estimated using the Barret-Joyner-Halenda (BJH) approximation. Thermogravimetry (TG) was carried out in an airflow using a TA Instruments Netzsch STA-409EP apparatus. The thermal measurements were conducted from $30^{\circ} \mathrm{C}$ to $1000{ }^{\circ} \mathrm{C}$ with $10{ }^{\circ} \mathrm{C} \mathrm{min}^{-1}$ as heating rate. The sample powder was chemically analyzed by inductively coupled plasma (ICP) emission spectroscopy (ICPS7500, Shimadzu, Japan).

\section{Solid state NMR studies}

Solid state NMR studies were performed on Avance III 300 and 500 Bruker spectrometers. In the case of Cross-Polarization (CP MAS) and HPDec MAS experiments, High Power Decoupling was applied during acquisition (spinal $64, v_{1 \mathrm{H}}=50 \mathrm{kHz}$ ). ${ }^{1} \mathrm{H}$ MAS NMR spectra were obtained at $300.29 \mathrm{MHz}$ (at 7.04 T) using a $7 \mathrm{~mm}$ diameter Bruker probe (MAS frequency, $5 \mathrm{kHz} ; 90^{\circ}$ pulse, recycle delay, $1 \mathrm{~s}$; number of scans NS, 4). $\left\{{ }^{1} \mathrm{H}\right\}-{ }^{13} \mathrm{C}$ CP MAS NMR experiments were performed at $75.51 \mathrm{MHz}$ (at 7.04 T) with a $7 \mathrm{~mm}$ diameter Bruker probe (MAS frequency, $5 \mathrm{kHz}$ ) using $90^{\circ}$ pulse, recycle delay of $1 \mathrm{~s}$, contact time of $1 \mathrm{~ms}$. NS was 8728 for c-HAp, 14320 for o-HAp, 6720 for s-HAp and 64544 for a-HAp. $\left\{{ }^{1} \mathrm{H}\right\}-{ }^{31} \mathrm{P}$ HPDec MAS NMR spectra were recorded using a $4 \mathrm{~mm}$ Bruker probe (MAS frequency, $14 \mathrm{kHz}$ ) at $202.49 \mathrm{MHz}$ (at $11.7 \mathrm{~T}$ ) using $30^{\circ}$ pulse, recycle delay of $10 \mathrm{~s}$ and NS, 128. $\left\{{ }^{1} \mathrm{H}\right\}-{ }^{31} \mathrm{P}$ CP-MAS
NMR experiments were carried out with a $4 \mathrm{~mm}$ diameter triple resonance Bruker probe (MAS frequency, $14 \mathrm{kHz}$ ) at a frequency of $121.56 \mathrm{MHz}$ (at $7.04 \mathrm{~T}$ ) using $90^{\circ}$ pulse, recycle delay of $2 \mathrm{~s}$, a contact time of $2 \mathrm{~ms}$ for routine experiments and NS, 280. A 2D HETeronuclear CORrelation $\left\{{ }^{1} \mathrm{H}\right\}-{ }^{31} \mathrm{P}$ HETCOR-CP experiment was performed for the c-HAp sample with a $1 \mathrm{~s}$ recycle delay, $10 \mathrm{~ms}$ contact time, 128 slices and NS, 360.

During 1D-processing, a line broadening (LB) of $10 \mathrm{~Hz}$ was applied for ${ }^{1} \mathrm{H}$ MAS spectra, $100 \mathrm{~Hz}$ for $\left\{{ }^{1} \mathrm{H}\right\}-{ }^{13} \mathrm{C} \mathrm{CP}$ MAS spectra, $50 \mathrm{~Hz}$ for $\left\{{ }^{1} \mathrm{H}\right\}-{ }^{31} \mathrm{P}$ HPDec MAS and CP MAS spectra. For the 2D $\left\{{ }^{1} \mathrm{H}\right\}-{ }^{31} \mathrm{P}$ HETCOR-CP experiment, LB was $100 \mathrm{~Hz}$ in direct dimension $\left({ }^{31} \mathrm{P}\right)$ and $200 \mathrm{~Hz}$ in indirect dimension $\left({ }^{1} \mathrm{H}\right)$.

\section{Results}

The chemical composition of the materials was first studied by TG analysis (Fig. 1). All samples show similar profiles with a first step in the $25{ }^{\circ} \mathrm{C}-200{ }^{\circ} \mathrm{C}$ temperature range corresponding to weakly-bound water desorption, and a second step between $200{ }^{\circ} \mathrm{C}$ and $500^{\circ} \mathrm{C}$ corresponding to the decomposition of organic matter incorporated in the apatite layers. In this last step, the relative weight loss for the different material is in the order c-HAp $\left(8 \mathrm{wt}^{\%} \%\right)>$ a-HAp $\left(4 \mathrm{wt}^{\%} \%\right)>\mathrm{s}-\mathrm{HAp}, \mathrm{o}-\mathrm{HAp}\left(3 \mathrm{wt}^{\%} \%\right)>$ HAp $\left(<2 \mathrm{wt}^{\%} \%\right)$.

The total organic carbon (TOC) as determined by CHONS elementary microanalysis technique, agrees fairly well with the $\mathrm{TG}$ analysis (Table 1). The molar $\mathrm{Ca} / \mathrm{P}$ ratio of the as-synthesized samples was also obtained by ICP-AES analyses and varies from 1.60 to 1.71 . It is interesting to note that the $\mathrm{Ca} / \mathrm{P}$ molar ratio of c-HAp is close to the one of the reference whereas the other additives lead to significantly higher $\mathrm{Ca} / \mathrm{P}$ ratio.

XRD patterns of as-prepared materials using carboxylate chelating agents after drying at $100{ }^{\circ} \mathrm{C}$ are shown in Fig. 2. A poorly crystalline structure is obtained for all products with a significant reduction in crystallinity in the presence of carboxylic acids. In particular, the diffraction peaks at $2 \theta \approx 32^{\circ}, 33^{\circ}$ and $34^{\circ}$ corresponding to the (211), (112) and (300) planes of the apatite structure (JCPDS No. 09-0432), that are clearly resolved in the HAp diffractogram, overlap due to band broadening for organically-modified apatites. In addition, additional peaks could be observed in the o-HAp diffractogram at $2 \theta \approx 25^{\circ}, 30^{\circ}$ and $38^{\circ}$ that may be attributed to the calcium oxalate monohydrate structure (JCPDS No. 20-231).

Infrared spectra of the as-prepared materials are shown in Fig. 3. On the pure HAp sample, vibrational bands at $c a .3570 \mathrm{~cm}^{-1}$ and $630 \mathrm{~cm}^{-1}$ are assigned to the $\mathrm{OH}$ groups, while sharp peaks at ca. 1090, 1030, 960, 605 and 565 and $470 \mathrm{~cm}^{-1}$ can be attributed to $\mathrm{PO}_{4}$ vibration. ${ }^{1}$ Vibration bands in the $1400-1450 \mathrm{~cm}^{-1}$ wavenumber range correspond to carbonate ions that could originate from the dissolution of surrounding $\mathrm{CO}_{2}$ during aqueous precipitation. ${ }^{1}$ In the presence of oxalic acid, an additional band at $1300 \mathrm{~cm}^{-1}$ appears corresponding to the $v_{\text {sym }}\left(\mathrm{COO}^{-}\right)$vibration band of oxalate ions whereas the the bands in the $1600-1650 \mathrm{~cm}^{-1}$ should correspond to both $\delta(\mathrm{H}-\mathrm{O}-\mathrm{H})$ of adsorbed water and $v_{\text {asym }}\left(\mathrm{COO}^{-}\right)$vibration. ${ }^{28}$ For s-HAp and aHAp, the corresponding asymmetric vibration bands of the carboxylate groups are also identified near 
$1550 \mathrm{~cm}^{-1}$ whereas the bands corresponding to the symmetric vibration expected near $1400 \mathrm{~cm}^{-1}$ are overlapping with carbonate bands. $^{29}$ In the case of c-HAp, because of the higher content in organic acid incorporated, this latter band is clearly visible at $1420 \mathrm{~cm}^{-1}$ together with the asymmetric band shifted to higher wavenumber ( $c a$. at $1590 \mathrm{~cm}^{-1}$ ). Noticeably, the relative intensity of the $\mathrm{OH}$ vibration bands at $3570 \mathrm{~cm}^{-1}$ and $630 \mathrm{~cm}^{-1}$ compared to the $\mathrm{PO}_{4}$ vibration bands at $602 \mathrm{~cm}^{-1}$ and $562 \mathrm{~cm}^{-1}$ is weaker in the presence of the organic acids.

The organically-modified samples were first analyzed by ${ }^{1} \mathrm{H}$ and $\left\{{ }^{1} \mathrm{H}\right\}-{ }^{13} \mathrm{C}$ CP solid state MAS NMR. The ${ }^{1} \mathrm{H}$ NMR spectra was similar for all samples, consisting of a broad peak centred at 4.8$4.9 \mathrm{ppm}$ and a narrow peak at $-0.4 \mathrm{ppm}$ which corresponds to water and hydroxyl groups from the hydroxyapatite structure, respectively (Fig. 4a). ${ }^{30}\left\{{ }^{1} \mathrm{H}\right\}-{ }^{13} \mathrm{C}$ CP MAS NMR spectra are shown on Fig. 4b. In the case of o-HAp, a single peak is observed at $167.9 \mathrm{ppm}$. For s-HAp, in addition to the signal at $31.8 \mathrm{ppm}$ corresponding to the carbon atoms of the molecule backbone,

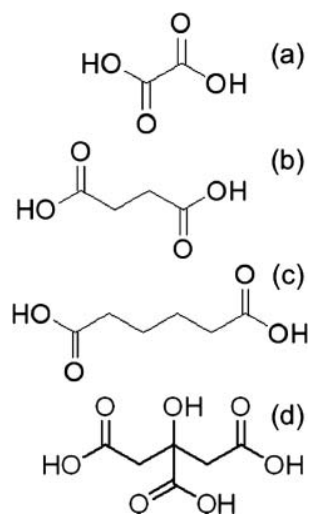

Scheme 1 Chemical structures of (a) oxalic acid, (b) succinic acid, (c) adipic acid, (d) citric acid.

Table 1 Chemical composition and porous characteristics of pure and carboxylate-modified apatites: calcium-phosphorus molar ratio $(\mathrm{Ca} / \mathrm{P})$, organic content ( $\%$ org), total organic carbon $(\% \mathrm{C})$, specific surface area $S_{B E T}$, porous volume $V_{p}$, pore size distribution $D_{p}$ and $C_{B E T}$ constant

\begin{tabular}{llllllll}
\hline Apatite & $\mathrm{Ca} / \mathrm{P}^{a}$ & $\% \mathrm{org}^{b}$ & $\% \mathrm{C}^{c}$ & $\begin{array}{l}S_{B E T}{ }^{d /} / \\
\mathrm{m}^{2} \mathrm{~g}^{-1}\end{array}$ & $\begin{array}{l}V_{p}{ }^{e} / \\
\mathrm{cm}^{3} \mathrm{~g}^{-1}\end{array}$ & $D_{p}{ }^{e} / \mathrm{nm}$ & $C_{B E T}$ \\
\hline HAp & 1.60 & $<2$ & 0.15 & 140 & 0.42 & $5-50$ & 310 \\
o-HAp & 1.71 & 3 & 1.30 & 170 & 0.38 & $5-40$ & 320 \\
S-HAp & 1.69 & 3 & 1.85 & 165 & 0.37 & $5-30$ & 150 \\
a-HAp & 1.69 & 4 & 2.65 & 160 & 0.36 & $5-15$ & 170 \\
c-HAp & 1.61 & 8 & 4.70 & 155 & 0.18 & $5-12$ & 80
\end{tabular}

${ }^{a}$ from ICP-AES, ${ }^{b}$ from TGA weight loss in the $200-500{ }^{\circ} \mathrm{C}$ range, ${ }^{c}$ from chemical analysis, ${ }^{d}$ from $\mathrm{N}_{2}$ isotherms with BET model, ${ }^{e}$ from $\mathrm{N}_{2}$ isotherms with BJH model. an intense peak is observed at $184.6 \mathrm{ppm}$ and a much weaker one at $169.1 \mathrm{ppm}$. A similar situation is found for a-HAp and c-HAp samples where, in addition to the signals of the carbon atoms of the molecule backbone in the $25-75 \mathrm{ppm}$ range, an intense signal at $185.1 \mathrm{ppm}$ and $180.3 \mathrm{ppm}$, respectively is found together with a weaker resonance at $169.7 \mathrm{ppm}$ and $169.9 \mathrm{ppm}$, respectively. Based on the literature, the low-field signals should correspond to carboxylate groups whereas high-field components should correspond to carbonate ions. One exception is observed for the oxalate compound where the signal from the carbon atom from the carboxylate groups is expected to be found at a close chemical shift to the carbonate one. ${ }^{31}$ Considering other samples, the signal attributed to carbonate ions is found between the expected resonance peaks corresponding to type $\mathrm{B}$ (i.e. phosphatesubstituting) and type A (i.e. hydroxyl-substituting) carbonates, and is broad, in agreement with the poor crystallinity of the materials. ${ }^{32,33}$

The materials were further studied by ${ }^{31} \mathrm{P}$ MAS NMR. The HPDEC-MAS ${ }^{31} \mathrm{P}$ spectra first appear similar for all samples, giving a single broad peak at $c a$. 2.8-2.9 ppm corresponding to the phosphorus atom of the phosphate groups in the apatite structure (Fig. 5a). ${ }^{32}$ However, the $\left\{{ }^{1} \mathrm{H}\right\}-{ }^{31} \mathrm{P}$ CP-MAS spectra suggests that the signal is asymmetrical with a narrow peak centered near $2.9 \mathrm{ppm}$ and a larger signal at a lower chemical shift value (Fig. 5b). This assumption was confirmed by varying the contact time of the CP experiment. The intensity of the low-field narrow signal slowly increases with contact time whereas at the same time the intensity of the high-field large signal rapidly increases and then decreases (ESI $\dagger$ ). It means that the first signal, which is a narrow Lorentzian-type component, is governed by a $T_{\mathrm{H}-\mathrm{P}}$ crossed relaxation law, that is typical for a rigid, well-crystallized structure in which both ${ }^{1} \mathrm{H}$ and ${ }^{31} \mathrm{P}$ nuclei are far from each other, as expected for apatite structures, ${ }^{30 \mathrm{~b}}$ while the second signal, a larger Gaussian-type component, follows a $T_{1 \rho}$ relaxation decay, with a maximum of intensity reached for short contact times, that is more likely to correspond to a poorly-organized hydrated layer. Moreover, the comparison of the linewidth of these two components recorded for a-HAp at two different magnetic fields $\left(B_{0}=7.0\right.$ and $\left.11.7 \mathrm{~T}\right)$ showed an apparent narrowing in ppm for the Lorentzian component but not for the Gaussian component $(\mathrm{ESI} \dagger)$. However the Lorentzian linewidth expressed in $\mathrm{Hz}$ is the same independently of the field. These observations support the assumption that the Lorentzian line is governed by $T_{2}$ * relaxation, that is typical of a well-defined environment, while the Gaussian component is related to site distribution, as usual for poorly-organised phases. Hence, the low-field resonance can be attributed to an ordered apatite whereas the high-field signal should correspond to a disordered, highly hydrated apatite layer, probably located at the surface of the material. To clarify this point, 2D $\left\{{ }^{1} \mathrm{H}\right\}-{ }^{31} \mathrm{P}$ HETCOR experiments were also performed, showing that two distinguishable correlations exist, first between the ${ }^{31} \mathrm{P}$ resonance at $2.9 \mathrm{ppm}$ and that at $-0.4 \mathrm{ppm}$ in the ${ }^{1} \mathrm{H}$ dimension and second, between the ${ }^{31} \mathrm{P}$ resonance at $1.9 \mathrm{ppm}$ and the ${ }^{1} \mathrm{H}$ broad resonance centered at $c a$. 4.8 ppm (Fig. 6). The cross-peak pattern is not symmetrical, in agreement with the previous assumption of the presence of two different signals for ${ }^{31} \mathrm{P}$ as well as for ${ }^{1} \mathrm{H}$. In addition, no correlation was observed neither between the ${ }^{31} \mathrm{P}$ narrow peak at $2.9 \mathrm{ppm}$ and the ${ }^{1} \mathrm{H}$ large resonance at $4.8 \mathrm{ppm}$ nor between the large ${ }^{31} \mathrm{P}$ peak at $1.9 \mathrm{ppm}$ 
and the narrow ${ }^{1} \mathrm{H}$ peak at $\quad-0.4 \mathrm{ppm}$, confirming our previous attributions.

Apatite powders were difficult to image by SEM due to the presence of organics, all samples mainly consisting of featureless granular materials with micron-size platelets being sometimes visible (ESI $\dagger$ ). TEM studies indicate that they consist of aggregated nanoparticles (Fig. 7). The HAp reference sample consists of platelets with an average size of $100 \mathrm{~nm}$. In contrast, all samples obtained with carboxylates consist of rod-like particles with some-times platelet morphologies being observed. Noticeably, whereas o-HAp and s-HAp show a rather open structure with individual particles being easy to distinguish, the density of aggregation appears to increase for a-HAp whereas c-HAp consists of hardly individualized nanoparticles glued together by an amorphous, probably organic, matrix. As far as nanoparticle size is concerned, their largest in-plane dimension is $20 \mathrm{~nm}$ for oHAp, $30 \mathrm{~nm}$ for s-HAp and $35 \mathrm{~nm}$ for a-HAp, all with a $5 \mathrm{~nm}$ standard deviation.

In the case of c-HAp, the average value is $20 \mathrm{~nm}$ with a $5 \mathrm{~nm}$ standard deviation.

Fig. 8a shows the full $\mathrm{N}_{2}$ adsorption-desorption isotherms of all solids dried at $100{ }^{\circ} \mathrm{C}$. In the case of HAp, o-HAp and s-HAp, these isotherms correspond to mesoporous materials. This is confirmed by calculation of the pore size distribution using the $\mathrm{BJH}$ model indicating a large distribution between $5 \mathrm{~nm}$ and 50 $\mathrm{nm}$ for HAp that slightly narrows down to $30 \mathrm{~nm}$ for s-HAp (Fig. $8 \mathrm{~b})$. In parallel, the specific surface area increases from $140 \mathrm{~m}^{2} \mathrm{~g}^{-1}$ for HAp to $c a .165 \mathrm{~m}^{2} \mathrm{~g}^{-1}$ for o-HAp and s-HAp (Table 1) while the porous volume $V_{p}$ is not significantly modified. For c-HAp, the $S_{B E T}$ value is similar to o-HAp and s-HAp but the porous volume $\left(0.18 \mathrm{~cm}^{3} \mathrm{~g}^{-1}\right)$ is much lower than all other samples. In the meantime, the pore size distribution is much narrower in the 10 $20 \mathrm{~nm}$ range and a new population below $10 \mathrm{~nm}$ is also apparent. a-Hap appears as an intermediate case with $S_{B E T}$ and porous volume values close to HAp, o-HAP and s-HAp but pore size distribution is closer to that of c-HAp. The $C_{B E T}$ constants were also calculated, which are indicative of the affinity of the material surface for the sorption gas. As shown in Table 1, HAp and oHAp have similar high values (ca. 300), s-HAp and a-HAp have intermediate parameters $(c a .150)$ and c-HAp has the lower $C_{B E T}$ (ca. 70)

\section{Discussion}

The formation of hydroxyapatite from $\mathrm{Ca}(\mathrm{OH})_{2}$ and $\mathrm{NH}_{4} \mathrm{H}_{2} \mathrm{PO}_{4}$ by neutralization is expected to proceed as follows:

$$
\begin{gathered}
10 \mathrm{Ca}(\mathrm{OH})_{2}+6 \mathrm{NH}_{4} \mathrm{H}_{2} \mathrm{PO}_{4}=\mathrm{Ca}_{10}\left(\mathrm{PO}_{4}\right)_{6}(\mathrm{OH})_{2} \\
+6 \mathrm{NH}_{4} \mathrm{OH}+12 \mathrm{H}_{2} \mathrm{O}-\log K>40
\end{gathered}
$$

Indeed, the solubility product of hydroxyapatite near neutral $\mathrm{pH}$ is so small that none of the additives used in this work in a $1: 0.15 \mathrm{Ca}:$ ligand ratio can inhibit its formation. ${ }^{34}$ However, they can interfere with the nucleation and/or growth reaction through their adsorption on the growing nuclei and/or particle surface. In this context, chemical analyses indicate that the $\mathrm{Ca}$ : ligand molar ratio in the final materials ranges from $1: 0.015$ for o-HAp and s-HAp to $1: 0.025$ for c-HAp, with an intermediate $1: 0.020$ ratio for a-HAp, indicating that $c a \cdot 10-15 \%$ of the ligand remained associated to the apatite structure

In the presence of carboxylic acids, the following reactions can also proceed: ${ }^{35}$

$$
\begin{gathered}
\mathrm{Ca}^{2+}+\mathrm{C}_{2} \mathrm{O}_{4}{ }^{2-}=\mathrm{Ca}\left(\mathrm{C}_{2} \mathrm{O}_{4}\right)_{s}-\log K=8-9 \\
\mathrm{Ca}^{2+}+\mathrm{C}_{4} \mathrm{H}_{4} \mathrm{O}_{4}{ }^{2-}=\mathrm{Ca}\left(\mathrm{C}_{4} \mathrm{H}_{6} \mathrm{O}_{4}\right)_{a q}-\log K=2-2.1 \\
\mathrm{Ca}^{2+}+\mathrm{C}_{6} \mathrm{H}_{8} \mathrm{O}_{4}{ }^{2-}=\mathrm{Ca}\left(\mathrm{C}_{6} \mathrm{H}_{8} \mathrm{O}_{4}\right)_{a q}-\log K=1.8-2.1 \\
\mathrm{Ca}^{2+}+\mathrm{C}_{6} \mathrm{H}_{5} \mathrm{O}_{7}{ }^{3-}=\mathrm{Ca}\left(\mathrm{C}_{6} \mathrm{H}_{5} \mathrm{O}_{7}\right)^{-}-\log K=3-4
\end{gathered}
$$

Oxalate establishes a weak monodentate binding with $\mathrm{Ca}^{2+}$. However, because it can bridge two calcium ions together, the precipitation of calcium oxalate occurs readily. Succinic and adipic acid act as stronger bidentate ligands for $\mathrm{Ca}^{2+}$. Finally, citric acid is a tridentate complex with $\mathrm{Ca}^{2+}$, resulting in the more stable complex in the here-studied series. The collected infra-red data suggest that the binding of organic acids to the apatite surface follows the expected coordination geometry for the corresponding $\mathrm{Ca}^{2+}$-complex. Especially, the difference $\Delta v$ between the $v_{\text {sym }}$ and $v_{\text {asym }}$ of carboxylate groups is large for oHAp, suggesting a monodentate binding and small for c-HAp, in favor of a chelating situation. ${ }^{35 \mathrm{c}}$ For s-HAp and a-HAp, the overlap between the carbonate band and $v_{\mathrm{sym}}\left(\mathrm{COO}^{-}\right)$band makes a precise determination difficult but an intermediate $\Delta_{\mathrm{n}}$ value is plausible, indicating a bidentate coordination. The organic content of the materials is also in agreement with the binding affinity of ligands except for s-HAp and a-HAp that incorporate significantly different amounts of acids despite similar $K$ values.

Ligand binding on the growing apatite particles can indeed perturb the structure of the outer apatite layer. $\left\{{ }^{1} \mathrm{H}\right\}-{ }^{31} \mathrm{P} \mathrm{CP}$ and HETCOR-CP NMR experiments suggest the presence of a poorlyordered highly-hydrated phase that may correspond to this surface layer. Noticeably, similar observations were already reported for synthetic and natural HAp nanocrystals. ${ }^{36}$ In particular, the coexistence of a broad and a narrow ${ }^{31} \mathrm{P}$ signal near $2.6-2.8 \mathrm{ppm}$ that exhibit different cross polarization time constants in $\left\{{ }^{1} \mathrm{H}\right\}-{ }^{31} \mathrm{P}$ $\mathrm{CP}$ experiments was described and attributed to the presence of both a crystalline apatite and a disordered apatite phase. ${ }^{36 a}$ The latter was suggested to correspond to the surface layer of HAp nanocrystals. Other studies suggest the presence of a carbonated amorphous calcium phosphate and/or the existence of $\mathrm{HOPO}_{3}{ }^{2-}$ groups. ${ }^{36 b, c}$ However, in all these studies, the ${ }^{31} \mathrm{P}$ spectra showed several signals, indicating that the phosphorus atoms also exists in other environments than the HAp structure. Therefore direct comparison with our data is difficult. However, the fact that the ${ }^{31} \mathrm{P}$ signal of the layer is slightly shifted compared to the HAp peak and does not correlate with protons from the $\mathrm{OH}$ groups of the apatite structure suggest that, due to the binding of carboxylate ligands to the calcium ions, less hydroxyl ions can be incorporated in this layer.

In parallel, the IR data shows the decrease of the intensity of the $\mathrm{OH}$ vibration band relative to the phosphate vibration bands in the presence of carboxylic acids, suggesting that ligands may substitute $\mathrm{OH}^{-}$groups rather than $\mathrm{PO}_{4}{ }^{3-}$. Alternatively, this effect can be observed in apatite structures with lower degrees of stoichiometry. In fact, for the reference apatite, the presence of carbonate ions, probably originating from dissolved ambient $\mathrm{CO}_{2}$, is suggested 
both by IR data and ICP/elemental analysis. In this case, the stoichiometry of the material should be evaluated by calculating the $\mathrm{Ca} /(\mathrm{P}+\mathrm{C})$, leading to a 1.59 value, in agreement with the previous hypothesis. However, such a calculation is not valid for the organically-modified samples because the experimental $\mathrm{Ca} / \mathrm{P}$ ratio is an average of the compositions of the surface layer and particle core. Due to the ligand binding to surface calcium ions, it is expected that the outer layer will be depleted in phosphate (and hydroxyl) groups, thus exhibiting a high $\mathrm{Ca} / \mathrm{P}$ ratio. As a result, if one assumes that the core particles have a similar composition as the reference apatite, the average $\mathrm{Ca} / \mathrm{P}$ ratio will be higher in the presence of ligands due to the outer layer contribution. Interestingly, in the case of c-HAp, the $\mathrm{Ca} / \mathrm{P}$ ratio is smaller than for the other ligands and closer to the one of the reference sample, i.e. the surface layer has a lower $\mathrm{Ca} / \mathrm{P}$ ratio. This may be due to the strong citrate-calcium affinity leading to the formation of complexes during the reaction that leave the material surface and are withdrawn during the washing procedure. Indeed a similar phenomena can occur for all ligands but it is expected to decrease with decreasing calcium-ligand affinity. One exception is observed for oxalate that forms an insoluble complex with calcium, explaining the formation of calcium oxalate monohydrate as revealed by XRD analysis.

The presence of organic ligands can also limit the size of growing HAp particles, by hindering the further addition of calcium, phosphate and hydroxyl on the growing particle surface. TEM and XRD studies indicate a loss in crystallinity and decrease in particle size in the presence of ligands compared to the pure HAp system. Due to the limited variations observed between the different organically-modified samples, it is difficult to establish a reliable classification. However, it can be noticed that o-HAp and c-HAp exhibit significantly smaller particle size when compared to a-HAp and s-HAp. This difference could be expected for oxalic acid, the ligand that exhibits the lowest affinity for calcium. In contrast, this effect is more difficult to fully explain for citric acid but it may be proposed that this ligand can act as a bridge to bind two calcium ions and is therefore twice as effective as succinic and adipic acid to perturb apatite growth for a similar initial concentration.

Coming to the porous features of the materials, it is worth noting that all modified apatites have a higher specific surface area $S_{B E T}$, lower pore volume $V_{p}$ and smaller average pore size than the reference sample, in agreement with the observed decrease in particle size. The decrease in $C_{B E T}$ values confirms that the ligand is located on the surface of the pores, i.e. on the particle outer layer. These ligands can also partially fill the pores of the materials, in agreement with TEM observations, explaining the decrease of the average pore size with organic content. Hence, it could be expected that c-HAp, with the highest organic content would present the lowest average pore size, as observed here. However, such a decrease should be correlated with an increase in specific surface area. This is not the case here but a significant decrease in pore volume is observed, meaning that the smallest pores become completely filled by the ligands and are no longer accessible to nitrogen during the sorption experiments. Noticeably, such a behavior is not observed for a-HAp despite a close pore size distribution. This can be attributed to the lower organic content as well as larger particle size for this material compared to c-HAp. The reason for the bimodal pore distribution observed in a-HAp and c-HAp is difficult to explain at this time. However it can be suggested that it exists for all organically-modified samples as a result of the rod-like morphology of the apatite nanocrystals which may lead to different packings and therefore different pore size. However it cannot be clearly distinguished for o-HAP and s-HAp due to the large pore distribution and become apparent only for a-HAp and c-HAp due to the much narrower distribution curves.

Finally, it is worth emphasizing the unexpected differences observed for succinic acid and adipic acid addition. These two ligands were initially selected because they have different inter-carboxylate chain length but exhibit similar calcium binding constants for complex formation in solution. Here, aHAp incorporates significantly more ligand than s-HAp which suggests that adipic acid has a significantly higher affinity for calcium on apatite surface. This may be due to the fact that the longer alkyl chain of adipic acid compared to succinic acid leads to a higher conformational flexibility and therefore a better adaptation of the chelating ligand to the steric constraint arising from the $\mathrm{PO}_{4}{ }^{3-} / \mathrm{OH}^{-}$environment of $\mathrm{Ca}^{2+}$ in the apatite structure.

\section{Conclusion}

Due to their similarity with the aspartic acid amino acid found in the protein backbone, the interactions of synthetic carboxylic acids on growing hydroxyapatite or hydroxyapatite surfaces have already been widely studied, especially for citric acid. ${ }^{22-27}$ Here we wished to take advantage of the strong carboxylate-apatite interactions to control both the structural and chemical features of HAp powders.

On the one hand, the incorporation of the here-selected ligands does not significantly improve the material surface area and porous volume compared to HAp obtained by the neutralization method. This latter parameter is even significantly lowered upon citric acid addition. On the other hand, some of these ligands significantly narrow the pore size distribution and modify the chemical nature of the surface (as indicated by $C_{B E T}$ constant). The first modification can be of primary importance because it allows a better control of the rate of apatite dissolution, foreseeing applications in bioactive and/or drug delivery materials. ${ }^{2,3}$ The second feature is also important in the medical field, because it can influence the interaction of the apatite surface with biomolecules or cells. ${ }^{5}$ Moreover, the modification of the sorption properties of apatite surfaces may be useful for remediation purposes, especially allowing enlargement of the chemical nature of organic pollutants that may be trapped within these promising low-cost/low-impact sorbents. $^{7,9}$

In this context, adipic acid appears as the most interesting additive as it shows comparable specific surface area, slightly lower porous volume but significantly narrower pore size distribution and lower $C_{B E T}$ compared to HAp. Indeed, further investigation of alternative carboxylic ligands is now necessary, for instance through the introduction of more hydrophobic molecules that may influence apatite porosity and surface to a larger extent. However, the here-provided comparison between adipic and succinic acids suggest that available data on ligand-calcium affinity in solution may not always constitute a sufficient basis for the selection of the most effective ligands for controlling the growth of hydroxyapatite. 


\section{Notes and references}

1 R. Z. Legeros, Calcium phosphates in oral biology and medicine, in: Monographs in oral science, Vol. 15, Ed. H. Meyer, Karger, Basel, 1991.

2 (a) S. V. Dorozhkin and M. Epple, Angew. Chem., Int. Ed., 2002, 41, 3130; (b) M. Epple, K. Gensan, R. Heumann, J. Klesing, A. Kotvun, S. Neumann and V. Sokolova, J. Mater. Chem., 2010, 20, 18.

3 (a) M. Vallet-Regi, Dalton Trans., 2006, 5211; (b) M. Vallet-Regi and D. Arcos, Biomimetic Nanoceramics in Climical Use, RSCPublishing, Cambridge, 2008.

4 J. C. Elliott, Structure and chemistry of the apatites and other calcium orthophosphates, Elsevier, Amsterdam, 1994.

5 C. Rey, C. Combes, C. Drouet, H. Sfihi and A. Barrough, Mater. Sci. Eng., C, 2007, 27, 198.

6 X. Chen, J. V. Wright, J. L. Conca and L. M. Peurrung, Environ. Sci. Technol., 1997, 31, 624.

7 A. Dybowska, D. A. C. Manning, M. J. Collins, T. Wess, S. Woodgate and E. Valsami-Jones, Sci. Total Environ., 2009, 407, 2953.

8 H. Tanaka, T. Watanabe and M. Chikazawa, J. Chem. Soc., Faraday Trans., 1997, 93, 4377.

9 (a) A. Laghzizil, M. Mekkaoui, P. Barboux and M. Ferhat, Toxicol. Environ. Chem., 2001, 81, 9; (b) A. Bahdod, S. El Asri, A. Saoiabi, T. Coradin and A. Laghzizil, Water Res., 2009, 43, 313.

10 S. Deb, M. Wang, K. E. Tanner and W. Bonfield, J. Mater. Sci.: Mater. Med., 1996, 7, 191.

11 H. Tanaka, A. Yasukawa, K. Kandori and T. Ishikawa, Langmuir, 1997, 13, 821.

12 Q. Liu, J. R. de Wijn, K. de Groot and C. A. van Blitterswijk, Biomaterials, 1998, 19, 1067.

13 S. C. D'Andrea and A. Y. Fadeev, Langmuir, 2003, 19, 7904.

14 A. Aissa, M. Debbabi, M. Gruselle, R. Thouvenot, P. Gredin, R. Traksmaa and K. Tonsuaadu, J. Solid State Chem., 2007, 180, 2273.

15 Y. Cui, Y. Liu, Y. Cui, X. Jing and P. Zhang, Acta Biomater., 2009, 5, 2680.

16 A. Zieba, G. Sethuraman, F. Perez, G. H. Nancollas and D. Cameron, Langmuir, 1996, 12, 2853.

17 (a) L. El Hammari, A. Laghzizil, A. Saoiabi, P. Barboux and M. Meyer, Colloids Surf., A, 2006, 289, 84; (b) L. El Hammari, H. Marroun, A. Laghzizil, A. Saoiabi, C. Roux, J. Livage and T. Coradin, J. Solid State Chem., 2008, 181, 848.

18 A. Bouladjine, A. Al-Kattan, P. Dufour and C. Drouet, Langmuir, $2009,25,12256$.

19 J. E. Barralet, M. Tremayne, K. J. Lilley and U. Gbureck, Chem. Mater, 2005, 17, 1313.

20 H. Qiu, J. Yang, P. Kodali, J. Koh and G. A. Ameer, Biomaterials, 2006, 27, 5845.

21 N. Ikawa, T. Kimura, Y. Oumi and T. Sano, J. Mater. Chem., 2009, 19, 4906.

22 (a) M. Johnsson, C. F. Richardson, J. D. Sallis and G. H. Nancollas, Calcif. Tissue Int., 1991, 49, 134; (b) V. K. Sharma, M. Johnsson, J. D. Sallis and G. H. Nancollas, Langmuir, 1992, 8, 676; (c) A. Tsortos and G. H. Nancollas, J. Colloid Interface Sci., 2002, 250, 159.

23 A. Lopez-Macipe, J. Gomez-Morales and R. Rodriguez-Clemente, J. Colloid Interface Sci., 1998, 200, 114.

24 N. Wada, K. Kanamura and T. Umegaki, J. Colloid Interface Sci., 2001, 233, 65 .

25 M. R. T Filgueiras, D. Mkhonto and N. H. de Leeuw, J. Cryst. Growth, 2006, 294, 60.

26 W. Jiang, H. Pan, Y. Cai, J. Tao, P. Liu, X. Xu and R. Tang, Langmuir, 2008, 24, 12446.

27 C. Li, Powder Technol., 2009, 192, 1.

28 A. Bernà, J. M. Delgado, J. M. Orts, A. Rodes and J. M. Feliu, Langmuir, 2006, 22, 7192.

29 I. Petrov and B. Soptrajanov, Spectrochim. Acta, 1975, 31 A, 309.

30 (a) J. P. Yesinowski and H. Eckert, J. Am. Chem. Soc., 1987, 109, 6274; (b) F. Pourpoint, C. Gervais, L. Bonhomme-Coury, T. Azaïs, C. Coelho, F. Mauri, B. Alonso, F. Babonneau and C. Bonhomme, Appl. Magn. Reson., 2007, 32, 435.

31 M. Bak, J. K. Thomsen, H. J. Jakobsen, S. E. Petersen, T. E. Petersen and N. C. Nielsen, J. Urol., 2000, 164, 856.

32 K. Beshah, C. Rey, M. J. Glimcher, M. Schimizu and R. G. Griffin, J. Solid State Chem., 1990, 84, 71.

33 (a) S. Hayakawa, K. Ohnishi, K. Tsuru, A. Osaka, E. Fujii, K. Kawabata, F. Babonneau and C. Bonhomme, Key Eng. Mater., 2006,
309-311, 503; (b) F. Babonneau, C. Bonhomme, S. Hayakawa and A. Osaka, Mater. Res. Soc. Symp. Proc., 2007, 9840984-MM0605 .

34 Z. F. Chen, B. W. Darvell and V. W. H. Leung, Arch. Oral Biol., 2004, 49, 359 .

35 (a) N. R Joseph, J. Biol. Chem., 1946, 164, 529; (b) D. M. Chang, J. Am. Oil Chem. Soc., 1983, 60, 618; (c) G. V. Mitrofonava, Russ. J. Appl. Chem., 2002, 75, 712 .

36 (a) T. Isobe, S. Nakamura, R. Nemoto, M. Senna and H. Sfihi, J. Phys. Chem. B, 2002, 106, 5169; (b) C. Jäger, T. Welzel, W. Meyer-Zaika and M. Epple, Magn. Reson. Chem., 2006, 44, 573; (c) Y.-H. Tseng, Y.-L. Tsai, T. W. T. Tsai, J. C. H. Chao, C.-P. Lin, S.-H. Huang, C.-Y. Mou and J. C. C. Chan, Chem. Mater, 2007, 19, 6088; (d) N. Nassif, F. Martineau, O. Syzgantseva, F. Gobeaux, M. Willinger, T. Coradin, S. Cassaignon, T. Azaïs and M. M. Giraud-Guille, Chem. Mater., 2010, 22, 3653 .

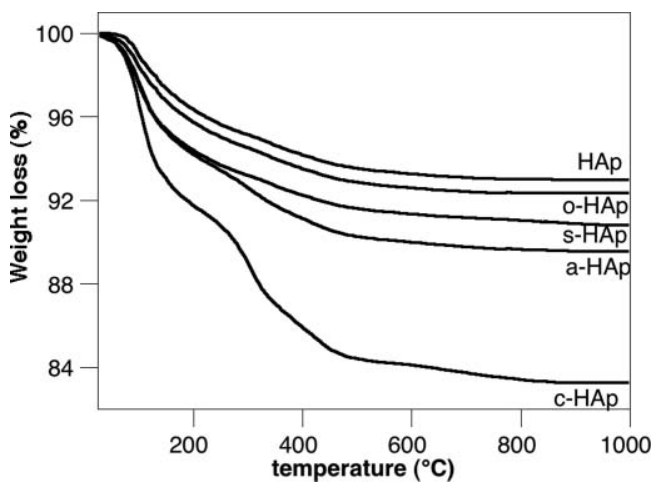

Fig. 1 TGA analyses of pure and carboxylate-modified apatites.

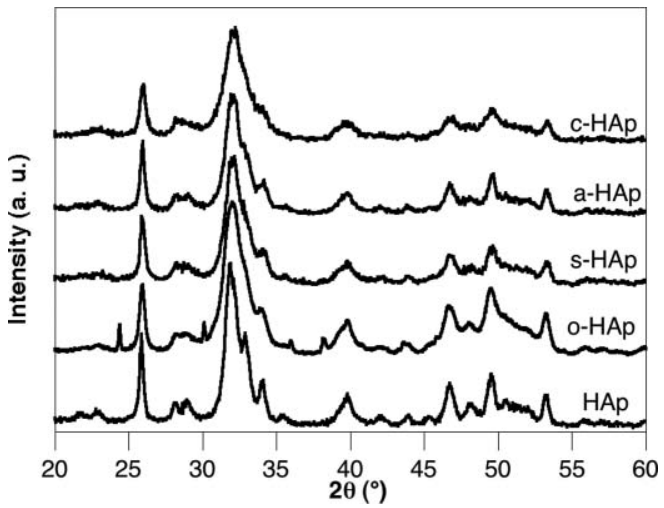

Fig. 2 XRD powder diffractograms of pure and carboxylate-modified apatites.

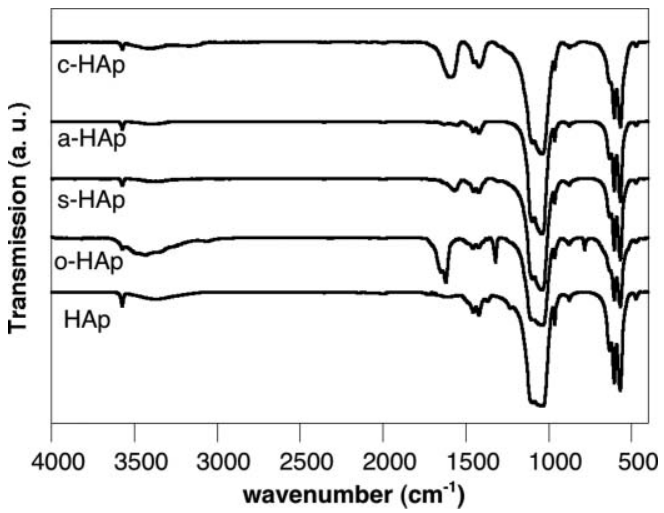

Fig. 3 Infra-red spectra of pure and carboxylate-modified apatites. 

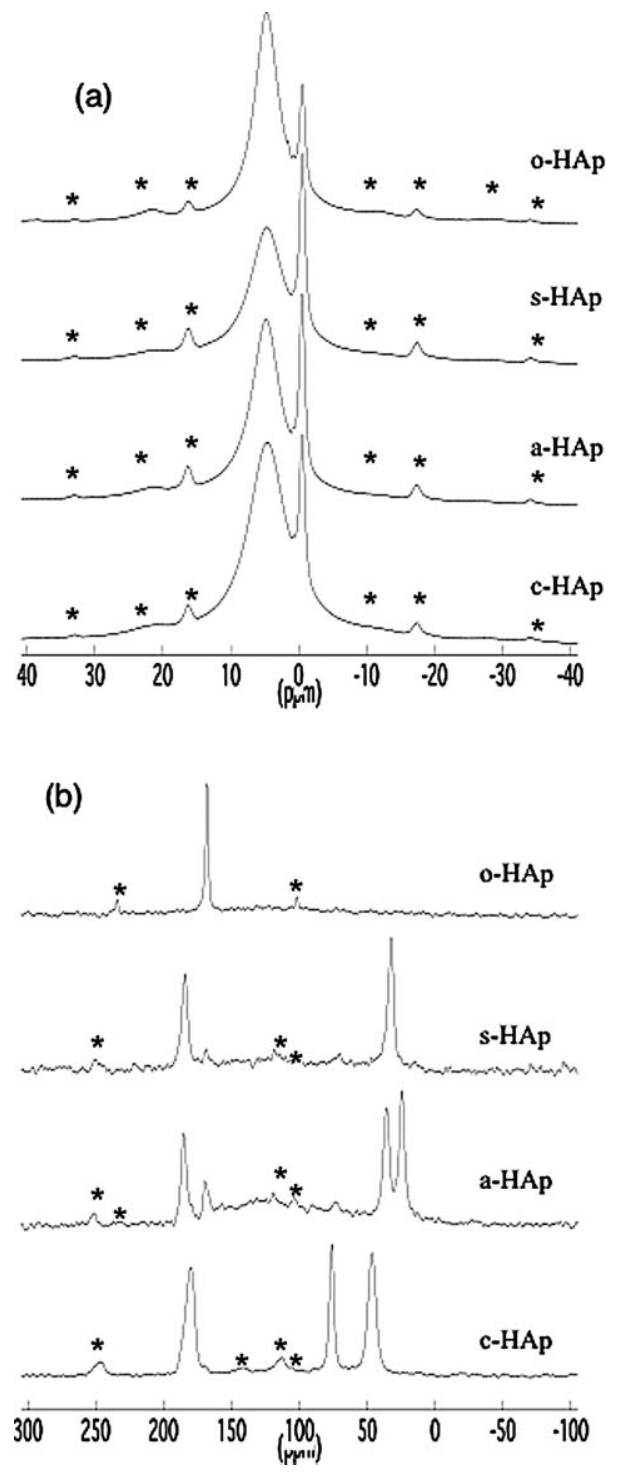

Fig. 4 (a) ${ }^{1} \mathrm{H}$ MAS and (b) $\left\{{ }^{1} \mathrm{H}\right\}-{ }^{13} \mathrm{C}$ CP MAS NMR spectra for pure and carboxylate-modified apatites (* indicate spinning side bands).

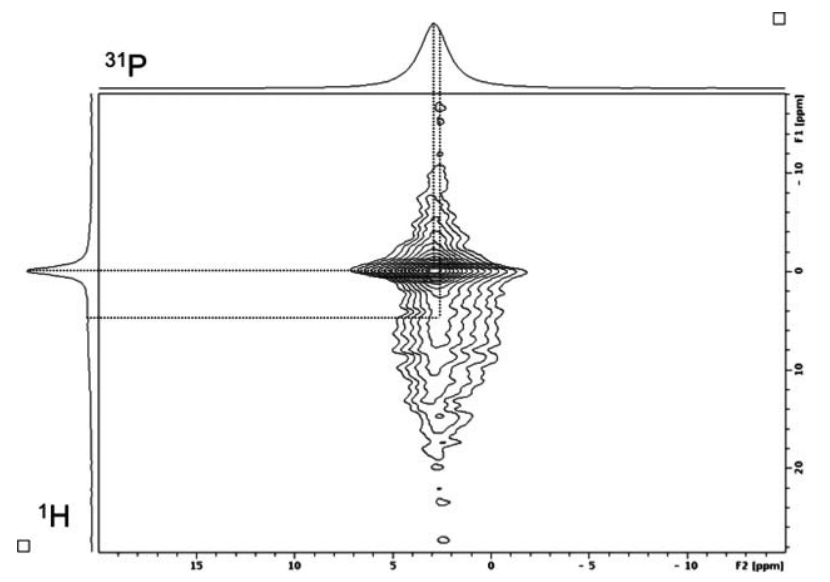

Fig. 6 2D $\left\{{ }^{1} \mathrm{H}\right\}-{ }^{31} \mathrm{P}$ HETCOR CP NMR spectrum of c-HAp (contact time $=10 \mathrm{~ms}$ ). Dashed lines were added as eye-guides for the readers.
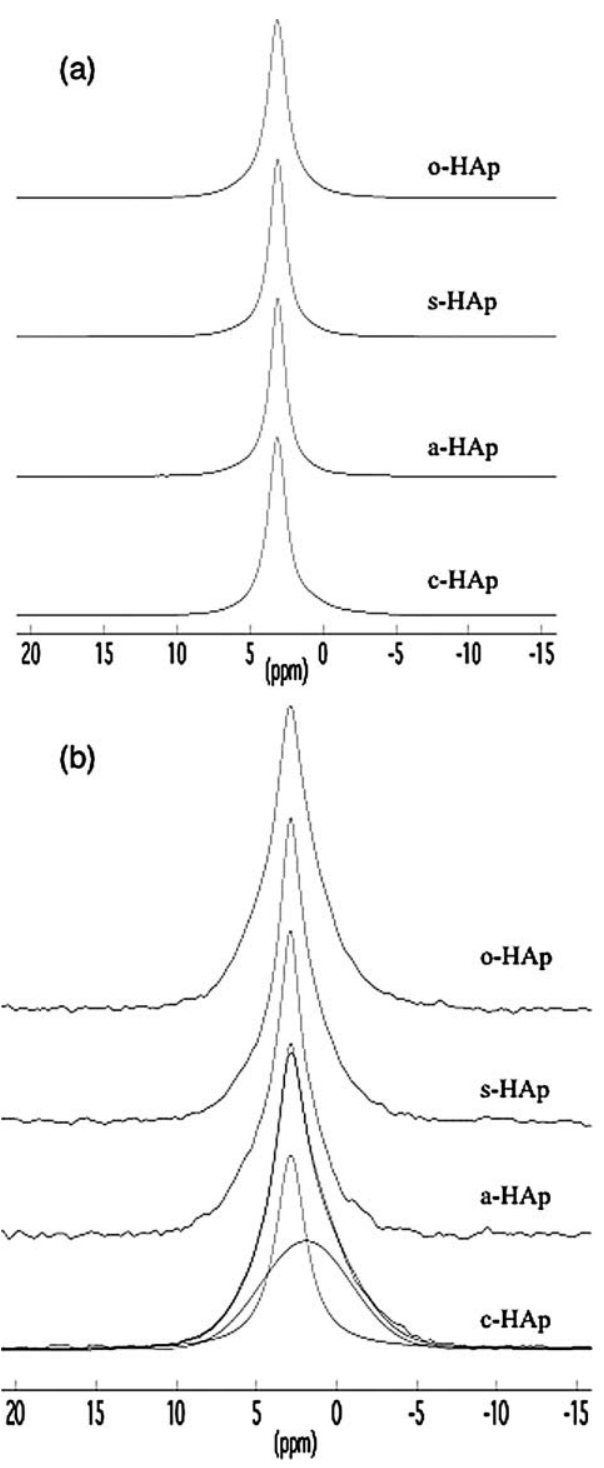

Fig. 5 (a) HPDEC-MAS ${ }^{31} \mathrm{P}$ and (b) $\left\{{ }^{1} \mathrm{H}\right\}-{ }^{31} \mathrm{P}$ CP MAS (contact time = $2 \mathrm{~ms}$ ) NMR spectra for pure and carboxylate-modified apatites. Deconvolution of the $\mathrm{CP}$ signal into two components is also shown for cHAp. 


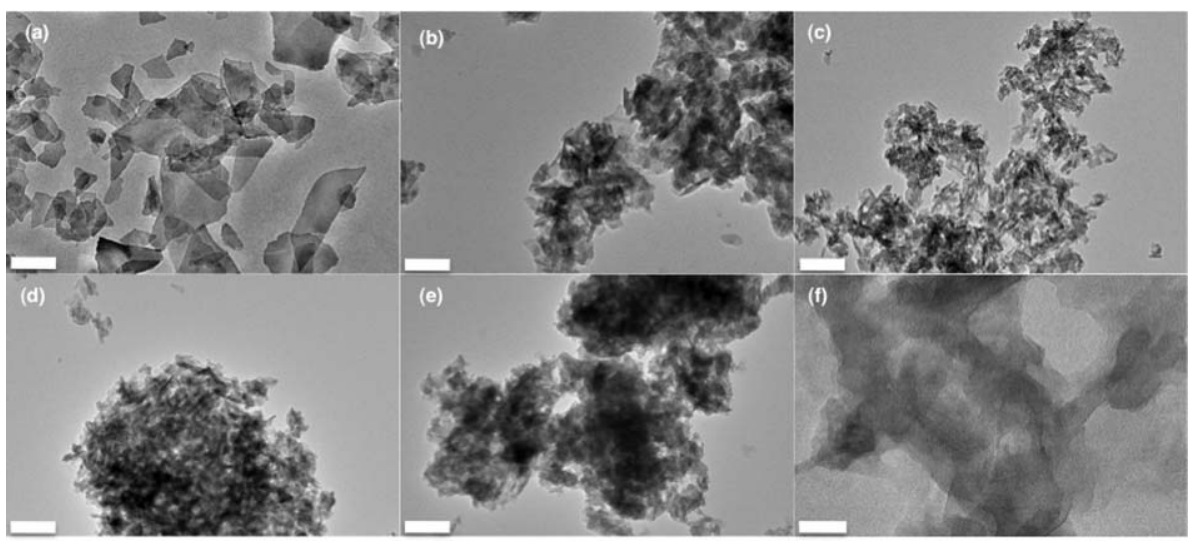

Fig. 7 TEM images of (a) HAp, (b) o-HAp, (c) s-HAp, (d) a-HAp and (e) c-HAp (scale bar = $100 \mathrm{~nm}$ ). (f) high magnification TEM image of c-HAp (scale bar $=20 \mathrm{~nm})$.
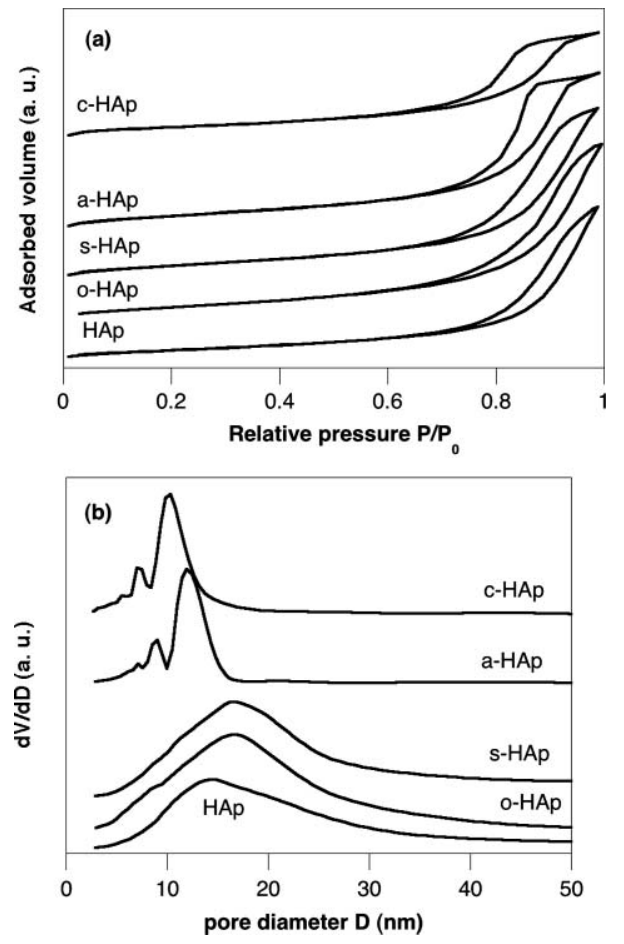

Fig. 8 (a) $\mathrm{N}_{2}$-sorption isotherms at $77 \mathrm{~K}$ and (b) pore size distribution from $\mathrm{BJH}$ analysis for pure and carboxylate-modified apatites. 


\section{Role of carboxylate chelating agents on the chemical, structural and textural properties of hydroxyapatite}

Karima Achelhi, ${ }^{a, b}$ Sylvie Masse, ${ }^{\mathrm{b}}$ Guillaume Laurent, ${ }^{\mathrm{b}}$ Ahmed Saoiabi, ${ }^{\mathrm{a}}$ Abdelaziz Laghzizil ${ }^{* a}$ and Thibaud Coradin $*^{b}$

Electronic Supplementary Information

ESI-1: $\left\{{ }^{1} \mathrm{H}\right\}-{ }^{31} \mathrm{P}$ cross-polarization curves for c-HAp

ESI-2 $\left\{{ }^{1} \mathrm{H}\right\}-{ }^{31} \mathrm{P}$ CP MAS NMR spectrum at $10 \mathrm{~ms}$ contact time at a) $7.0 \mathrm{~T}$ and b) $11.7 \mathrm{~T}$.

ESI-3: SEM images of carboxylate-modified samples 
ESI-1: $\left\{{ }^{1} \mathrm{H}\right\}-{ }^{31} \mathrm{P}$ cross-polarization curves for c-HAp

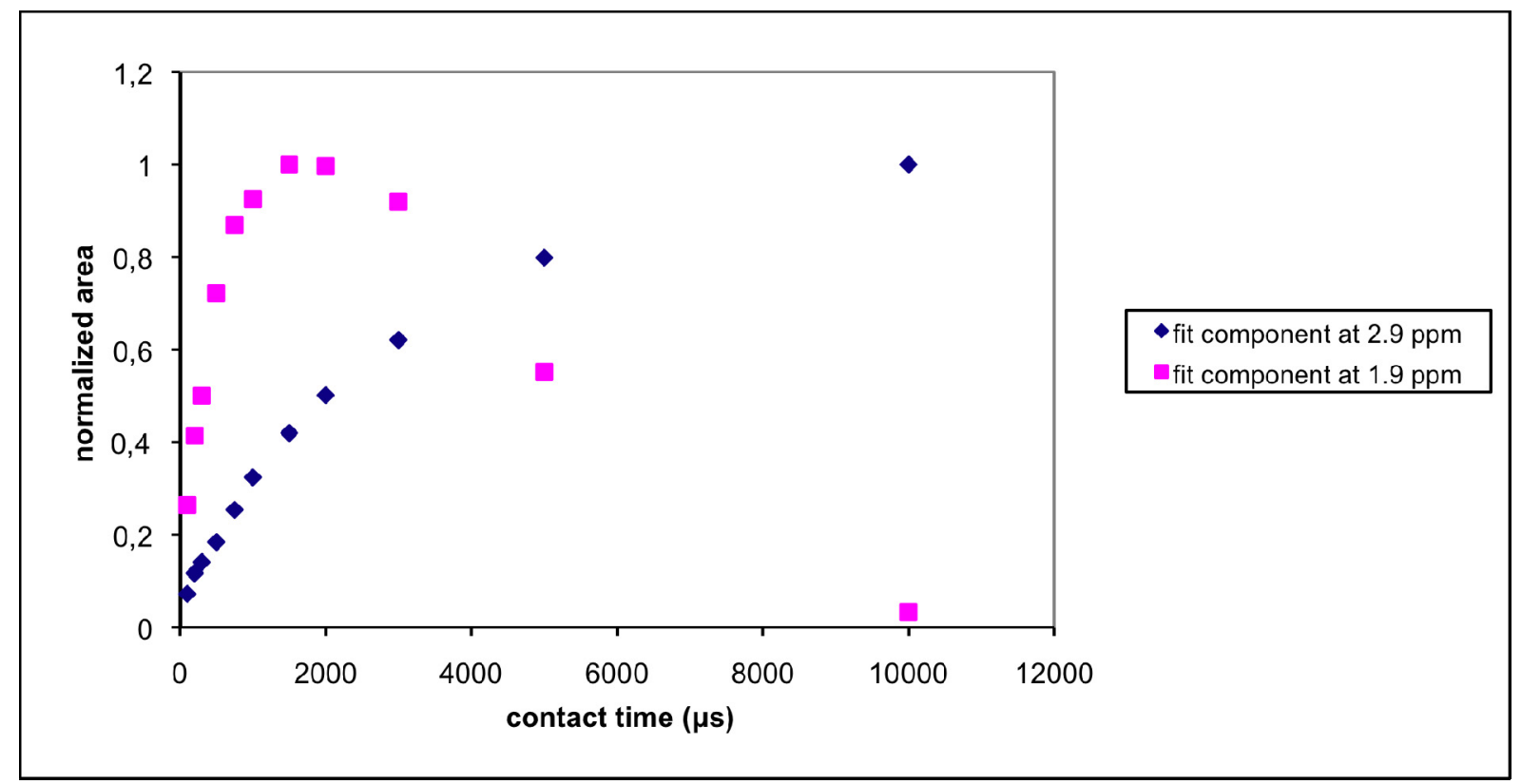


ESI-2: $\left\{{ }^{1} \mathrm{H}\right\}-{ }^{31} \mathrm{P}$ CP MAS NMR spectrum at $10 \mathrm{~ms}$ contact time at a) $7.0 \mathrm{~T}$ and b) $11.7 \mathrm{~T}$.

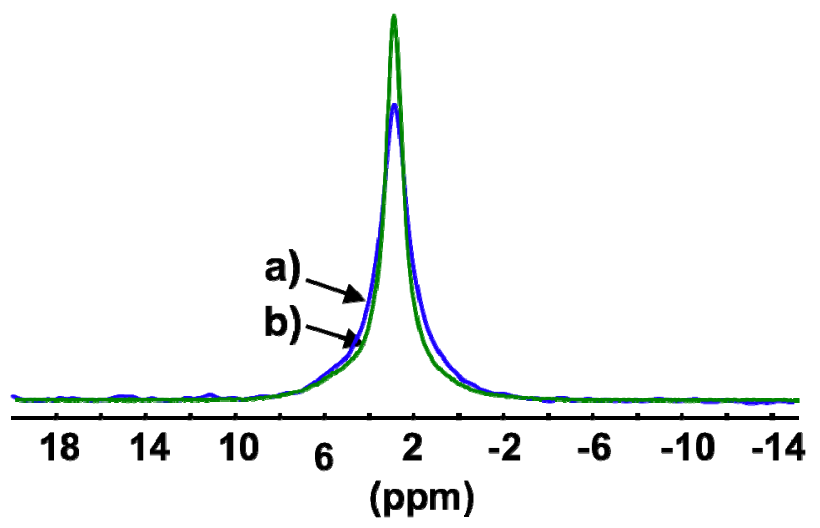


ESI-3: SEM images of all samples

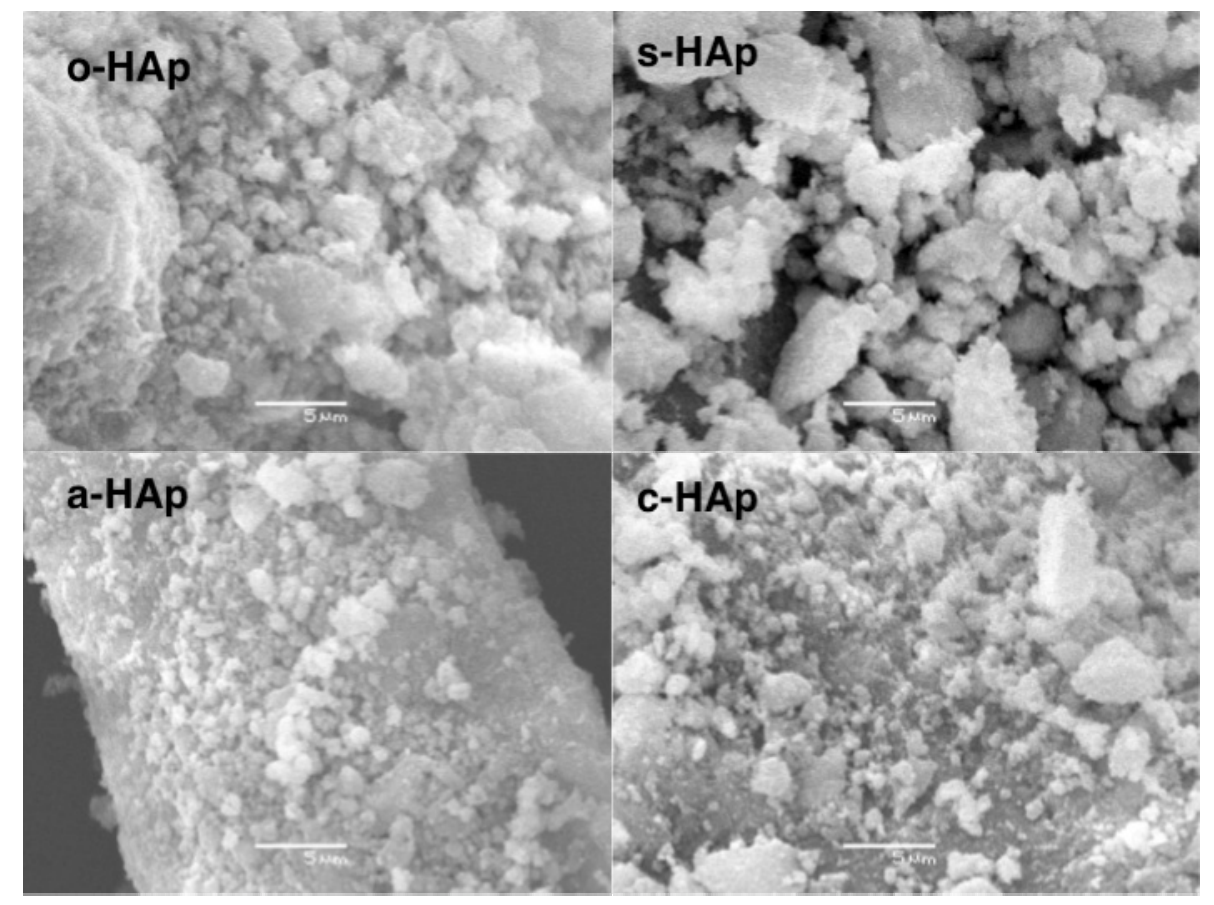

